\title{
COMPETITIVE PROFILE DIFFERENCES BETWEEN THE BEST-RANKED EUROPEAN FOOTBALL CHAMPIONSHIPS
}

original paper

doi: https://doi.org/10.5114/hm.2017.73619

\author{
ÁNGEL VALES-VÁZQUEZ ${ }^{1}$, CARLOS CASAL-LÓPEZ ${ }^{1}$, PEDRO GÓMEZ-RODRÍGUEZ ${ }^{1}$, \\ HUGO BLANCO-PITA ${ }^{2}$, JAIME SERRA-OLIVARES ${ }^{3,4}$ \\ ${ }^{1}$ Faculty of Sport Sciences and Physical Education, University of A Coruña, A Coruña, Spain \\ ${ }^{2}$ Spanish Professional Football League (LaLiga), Madrid, Spain \\ ${ }^{3}$ University of Castilla-La Mancha. Faculty of Education, Albacete, Spain \\ ${ }^{4}$ Catholic University of Temuco, Temuco, Chile
}

\begin{abstract}
Purpose. The aim of the study was to compare the competitive profiles of the best-ranked European football championships. Methods. The final rankings $(n=30)$ and the final scores of the matches played in the 2012, 2013, 2014, 2015, and 2016 seasons $(n=10,465)$ of the best-ranked European football championships (Spanish LaLiga, English Premier League, German Bundesliga, Portuguese Liga Portugal, French Ligue 1, and Italian Serie A) were analysed. The instrument used was the Battery of Indicators for the Assessment of Competitive Profile of a Championship. The competitive profile was analysed in three dimensions and their correspondent measurement indices: (1) degree of excellence: International Achievement and Classification Dominance indices; (2) equality of teams: Classification Compactness, Performance Sustainability, and Home Advantage indices; (3) type of matches: Match Openness, Match Equality, and Result Uncertainty indices. ANOVA one-way analysis of variance and Bonferroni post-hoc adjustment were used.

Results. Significant differences were shown among the main European championships in the International Achievement $(p=0.003)$, Classification Dominance $(p=0.001)$, Classification Compactness $(p=0.009)$, Match Openness $(p=0.000)$, and Match Equality ( $p=0.008)$ indices.

Conclusions. LaLiga Spanish championship stands out as the only instance of a quality competitive profile. Consequently, LaLiga occupies the highest position in the indices related with the international prestige and the competitive quality of the teams $(p<0.001)$.
\end{abstract}

Key words: European football, competitive profile, LaLiga, Ligue 1, Serie A, Premier League, Bundesliga, Liga Portugal

\section{INTRODUCTION}

The specialized literature in the field of football research has acquired particular relevance in recent decades. Main research lines are focused on ascertaining the main demands of football in order to transfer this knowledge to fields such as physical and tacticaltechnical optimization of the training and competitive processes [1-5], strategies for the socio-economic management [6,7], or the implementation of more efficient protocols for injury prevention and recovery $[8,9]$. In this line, studying the potential similarities and differences between the best championships that take place in Europe is essential for an integral management of teams, clubs, and competitions. However, competitive characteristics analysis has been carried out through the application of unidirectional indicators (i.e. the study of the economic status of the teams, the physical fitness differences or tactical performance, in isolation). Thus, a different perspective of analysis is necessary.

The comparison of different models of management led to the establishment of various rankings of excellence at the international football level. The best examples are studies oriented to the analysis of the morpho-functional peculiarities of the game [10-12], the economic and financial variables and their influence

Correspondence address: Ángel Vales-Vázquez, Facultad de Ciencias del Deporte y la Educación Física, Universidade da Coruña, Avd. Che Guevara 121. Bastiagueiro, Oleiros. 15179, A Coruña, Spain, e-mail: avales@udc.es

Received: November 15, 2017

Acepted for publication: January 10, 2018

Citation: Vales-Vázquez Á, Casal-López C, Gómez-Rodríguez P, Blanco-Pita H, Serra-Olivares J. Competitive profile differences between the best-ranked european football championships. 2017;18(5)special/issue:97-105; doi: https://doi.org/10.5114/ hm.2017.73619. 
Á. Vales-Vázquez et al., European football competitive profile

on variation in the qualifying performance [6, 13-16], and the assessment of the degree of competitive balance of the teams during the championship [7, 17-19]. Overall, the common denominator that typifies most of the previous studies is their interest in highlighting the main differentiating features that characterize teams taking part in the same championship. Some examples are those about comparative studies at the local level or international comparative studies from an economic-financial or sport-competitive point of view (e.g. studies that analysed technical-tactical efficiency indices, physical workload indices, financial robustness indices, classification balance indices, etc.) [7, 17-20].

Regarding the studies that focus on the comparative analysis of the competitive balance degree of the teams participating in a championship, adapted indicators from the economic field have been used traditionally (e.g. the Gini index, Herfindahl and Hirschman index, Palma index, Lorenz dominance curve) $[6,11$, $13,17,18]$. In this sense, certain deficits were observed in the implementation of more specific indicators of sports science itself. From a conceptual point of view, the competitive balance of a sports competition represents a measure of the degree of imbalance between the teams taking part in the same championship, by calculating the inequality in the distribution of the points that each team obtains in the final classification [7]. For example, it has been observed in the case of the bestEuropean championships. Michie and Oughton [18], Goossens [17], Gasparetto and Barajas [21], as well as Montes and Sala [22] have concluded that the competitive performance supremacy of a small group of teams in a championship represents a characteristic pattern of the most representative championships that operate in the European territory.

However, literature suggests that championships with a good competitive balance are more attractive for the spectators since they increase the degree of uncertainty of the matches and the final classification of the teams [6, 18, 21]. Other studies, such as those of PérezGonzález et al. [7] and Boor et al. [16], point out that the classification equality of teams belonging to the same championship has a positive influence on the various types of revenue received by clubs (i.e. box office and stadium operation revenue, sponsorship and marketing revenue, and revenue from broadcasting rights). Consequently, it has an effect on the capacity of the championship to recruit players and to develop teams of a higher competitive level.

In this context, it seems clear that the study of the competitive profile factors of teams and championships that comprise the European football provides crucial information that could be used for improving the elite sport management process [6, 18, 21]. Nevertheless, the classification of the competitive characteristics of a championship has been carried out through the application of unidirectional indicators. Thus, it has been based on the use of assessment tools and analysis processes characterized by a reductionist point of view. For this reason, and in order to enable the development of a more detailed and practical analysis of the competitive peculiarities at structural and functional levels, a new approach of study is being developed.

The purpose of this research is to compare the competitive profile of the best-ranked championships that currently comprise the European football scene (Spanish LaLiga, English Premier League, German Bundesliga, Portuguese Liga Portugal, French Ligue 1, and Italian Serie A) by using a contextualized instrument of performance indicators. The main objective of the analysis is to detect differences in relation to three dimensions: the degree of excellence of a championship, the degree of equality of performance in the teams taking part in a championship, and the types of matches played in a championship. In this respect, the main hypothesis is that the championships will show differences in the three dimensions analysed.

\section{MATERIAL AND METHODS}

\section{Design and sample}

A comparative study was developed in order to analyse the overall competitive profiles of the main championships that make up the current European football scene, according to the UEFA ranking of club competitions [23]: the Spanish LaLiga, English Premier League, German Bundesliga, Portuguese Liga Portugal, French Ligue 1, and Italian Serie A championships. The final rankings and the final scores of the matches played in the 2012, 2013, 2014, 2015, and 2016 seasons in each championship were registered. Therefore, the total sample consisted of 30 final rankings and the results of 10,465 matches.

\section{Instrument and procedures}

An ad-hoc instrument was designed for the analysis of the competitive profile of the championships: the Battery of Indicators for the Assessment of Competitive Profile of a Championship (BIACPC). The BIACPC battery is a multi-dimensional tool in nature. It is structured in 3 dimensions of analysis and their specific indices: (1) degree of excellence: International Achievement Index (IAI) and Classification Dominance Index (CDI-75); (2) team equality: Classification 
Table 1. Indices associated with the excellence of the championships dimension for the assessment of the competitive profile of a championship

\section{EXCELLENCE OF THE CHAMPIONSHIPS}

Purpose: To evaluate the degree of competitiveness and international prestige of teams belonging to the same championship

\section{ASSOCIATED INDICES}

International Achievement Index (IAI)

- Focus: Quantification of the international achievements of teams belonging to the same championship.

- Calculation procedure: [(Champions League winner $=3)+($ Champions League runner-up $=1.5)+($ UEFA Europa League winner $=2)+($ UEFA Europa League runner-up $=1)+($ FIFA Club World Cup winner $=1)+($ FIFA Club World Cup runner-up $=0.5)+($ UEFA Super Cups winner $=1)+($ UEFA Super Cup runner-up $=0.5)] /$ number of championship teams.

- Interpretation: Obtaining high values in the IAI of a championship is indicative of a high degree of international prestige of the teams belonging to the championship involved. In turn, low values point at a moderate or reduced degree of international prestige.

\section{Classification Dominance Index (CDI-75)}

- Focus: Quantification of the number of excellent teams in the same championship that monopolize the classification dominance of the same championship.

- Calculation procedure: Number of teams belonging to the same championship that accumulate $75 \%$ or more of the points in play at the end of the season.

- Interpretation: High values in the CDI-75 indicate championships where there is a higher number of excellent teams that compete for supremacy of the championship. In turn, low values point at championships in which there is an absence of excellent teams or a monopoly of a small number of teams that compete for supremacy of the championship.

Table 2. Indices associated with the team equality dimension for the assessment of the competitive profile of a championship

\section{TEAM EQUALITY}

Purpose: To evaluate the degree of equality in the performance of the teams taking part in the championship

\section{ASSOCIATED INDICES}

Classification Compactness Index (CCI)

- Focus: Quantification of the degree of equality in the final classification of teams participating in the same championship.

- Calculation procedure: Typical deviation of points obtained in the final classification of the season by each team participating in the same championship.

- Interpretation: Low values in the CCI of a championship indicate a high degree of classification compactness among the teams. In turn, high values point at a high degree of dispersion of the teams in the final classification.

\section{Performance Sustainability Index (PSI)}

- Focus: Quantification of the degree of difficulty encountered by teams belonging to the same championship to put together a string of victories.

- Calculation procedure: The average of the best sequences of consecutive victories achieved by each team belonging to the same championship.

- Interpretation: Low values in the PSI of a championship indicate great difficulty in putting together a string of victories and sustaining good results over time. In turn, high values point at championships in which the teams have less difficulties reaching consistent and durable high performance.

Home Advantage Index (HAI)

- Focus: Quantification of the incidence or advantageous effect of playing as the home team on the final result of matches belonging to the same championship.

- Calculation procedure: Percentage of matches belonging to the same championship the final result of which is a victory for the home team.

- Interpretation: Low values in the HAI of a championship indicate a diminished effect of the advantage of playing at home. In turn, high values point at a marked influence of this effect. 
Á. Vales-Vázquez et al., European football competitive profile

Table 3. Indices associated with the type of matches dimension for the sessment of the competitive profile of a championship

\section{TYPES OF MATCHES}

Purpose: To evaluate the degree of openness and competitiveness in matches played in the championship

\section{ASSOCIATED INDICES}

Match Openness Index (MOI)

- Focus: Quantification of the degree of difficulty that matches belonging to the same championship have to record final scores with a high number of goals.

- Calculation procedure: Average of goals per game during a championship.

- Interpretation: High values in the MOI of a championship point at the presence of open game dynamics in its matches. In turn, low values are indicative of championships that feature a lot of closed or defensive play.

Match Equality Index (MEI)

- Focus: Quantification of the size of the differences in the final scores of matches belonging to the same championship.

- Calculation procedure: Percentage of tied matches or those with a difference of one goal in the final score of matches belonging to the same championship.

- Interpretation: High values in the MEI of a championship indicate a high degree of competitive balance of the matches. In turn, low values point at a low or moderate degree of competitive balance of the matches.

Result Uncertainty Index (RUI)

- Focus: Quantification of the entertainment value, closeness, and degree of competitive tension of the scores in matches belonging to the same championship.

- Calculation procedure: Percentage of matches of the same championship in which the score changes after the $80^{\text {th }}$ minute.

- Interpretation: High values in the RUI of a championship point at the occurrence of matches in which there is a high degree of competitive tension and uncertainty in the final result. In turn, low values indicate championships the matches of which entail a low or moderate degree of competitive tension and uncertainty in the final results.

Compactness Index (CCI), Performance Sustainability Index (PSI), and Home Advantage Index (HAI); (3) type of the matches: Match Openness Index (MOI), Match Equality Index (MEI), and Result Uncertainty Index (RUI). All dimensions and indices are explained in Tables 1-3.

Six experts from the academic and professional soccer training fields were consulted to verify the content validity of the BIACPC. The procedure had two phases. In the first one, experts were informed of the objectives and applications of the measurement instrument and of the content, meaning, calculation procedures, and interpretation of each index used to evaluate the competitive profile of a championship. In the second phase, they were asked to assess the suitability of the 3 dimensions of analysis and the indices. The experts showed concordance percentages (based on the degree of agreement) higher than 93\% in all items and cases subject to control. Thus, no substance changes were introduced to the battery. Only 2 indicators were adapted in accordance with the experts review. In the same line, the battery showed a suitable internal consistency $(\alpha>0.85)$, and the correlation between the championship ranking and the battery indices criterion revealed reasonable evidence for assessing the instrument reliability $(r>0.7 ; p<0.01)$. Fi- nally, the variable championship was crucial for the competitive profile of the teams/championships, supporting the construct and concurrent validity. These results verify the validity of the battery for this study.

\section{Data analysis}

The data analysis was performed with the IBM SPSS version 20.0 statistical package. Mean and standard deviation values associated with each index of the 6 championships under study were calculated. The normality and homogeneity of the variances were tested with the use of the Kolmogorov-Smirnov and Levene statistic tests. It was noted that the sample met the requirements for the assumption of normality and homogeneity. Therefore, one-way ANOVA variance analysis and the Bonferroni post-hoc test were performed to analyse possible differences between the championships in each of the competitive profile indices of the BIACPC. In the first stage, the first dimension, concerning the excellence of the championship, was analysed; then, the championships were compared with regard to the equality of their teams; finally, the championships were compared with the consideration of the type of matches that took place. A comparison model with the level of significance set at $p<0.05$ was developed. 


\section{RESULTS}

Tables 4-6 show mean values for all dimensions and indices analysed in the championships under study. Significant differences were observed between the championships in the competitive profile dimensions and measuring indices. More in detail, differences were significant in the 2 indices of the excel-

Table 4. Excellence of the championships analysed

\begin{tabular}{lcccc} 
Championship & \multicolumn{2}{c}{$\begin{array}{l}\text { International } \\
\text { Achievement* }\end{array}$} & \multicolumn{2}{c}{$\begin{array}{c}\text { Classification } \\
\text { Dominance* }\end{array}$} \\
& $\mathrm{M}$ & $\mathrm{SD}$ & $\mathrm{M}$ & $\mathrm{SD}$ \\
LaLiga & 0.29 & 0.19 & 2.20 & 0.83 \\
\hline Premier League & 0.07 & 0.08 & 1.00 & 0.70 \\
\hline Bundesliga & 0.08 & 0.15 & 1.20 & 0.44 \\
\hline Serie A & 0.01 & 0.03 & 0.80 & 0.44 \\
\hline Ligue 1 & 0.00 & 0.00 & 0.40 & 0.54 \\
\hline Liga Portugal & 0.02 & 0.03 & 1.80 & 0.44
\end{tabular}

* Means difference is significant at the level of 0.05 lence of the championships dimension (International Achievement Index and Classification Dominance Index), in 1 of the indices of the team equality dimension (Classification Compactness Index), and in 2 of the 3 indices of the type of matches dimension (Match Openness Index and Match Equality Index).

In this sense, LaLiga scored significantly higher results in the International Achievement Index than Serie A $(F=5.015 ; p=0.007)$, Ligue $1(F=5.015 ; p=$ $0.004)$, and Liga Portugal championships $(F=5.015$; $p=0.010$ ). Although differences were not significant, LaLiga scored higher values near to be significant than the Premier League $(F=5.015 ; p=0.062)$ and Bundesliga $(F=5.015 ; p=0.093)$. Regarding the second index of the excellence of a championship dimension, the Classification Dominance Index, LaLiga reached significantly higher values than the Premier League $(F=6.267 ; p=0.057)$, Serie $\mathrm{A}(F=6.267 ; p=$ $0.015)$, and Ligue $1(F=6.267 ; p=0.001)$. Finally, the Liga Portugal championship also scored significantly higher results than Ligue $1(F=6.267 ; p=0.001)$ in this index. Significant differences were not observed in any other case in this dimension.

Table 5. Team equality between the teams of the championships analysed

\begin{tabular}{lcccccc} 
& \multicolumn{2}{c}{ Classification Compactness* } & Performance Sustainability & \multicolumn{3}{c}{ Home Advantage } \\
Championship & $\mathrm{M}$ & $\mathrm{SD}$ & $\mathrm{M}$ & $\mathrm{SD}$ & $\mathrm{M}$ & $\mathrm{SD}$ \\
\hline LaLiga & 17.85 & 1.42 & 3.67 & 0.16 & 47.89 & 1.93 \\
\hline Premier League & 16.82 & 1.42 & 3.44 & 0.40 & 44.47 & 2.14 \\
\hline Bundesliga & 15.12 & 1.33 & 3.42 & 0.27 & 45.36 & 2.12 \\
\hline Serie A & 16.49 & 1.66 & 3.66 & 0.25 & 45.15 & 2.98 \\
\hline Ligue 1 & 14.43 & 0.94 & 3.32 & 0.22 & 45.10 & 2.28 \\
\hline Liga Portugal & 16.94 & 1.57 & 3.42 & 0.33 & 44.81 & 1.94
\end{tabular}

* Means difference is significant at the level of 0.05

Table 6. Type of matches of the championships analysed

\begin{tabular}{lcccccc} 
& \multicolumn{2}{c}{ Match Openness* } & \multicolumn{2}{c}{ Match Equality* } & \multicolumn{2}{c}{ Result Uncertainty } \\
Championship & $\mathrm{M}$ & $\mathrm{SD}$ & $\mathrm{M}$ & $\mathrm{SD}$ & $\mathrm{M}$ & $\mathrm{SD}$ \\
\hline LaLiga & 2.75 & 1.75 & 61.52 & 1.34 & 17.16 & 1.30 \\
\hline Premier League & 2.73 & 1.70 & 64.94 & 4.81 & 19.42 & 2.53 \\
\hline Bundesliga & 2.91 & 1.71 & 57.97 & 4.27 & 16.83 & 1.48 \\
\hline Serie A & 2.64 & 1.66 & 63.05 & 2.87 & 18.21 & 1.86 \\
\hline Ligue 1 & 2.51 & 1.59 & 65.37 & 0.99 & 17.79 & 1.75 \\
\hline Liga Portugal & 2.60 & 1.61 & 63.64 & 1.21 & 17.72 & 1.92
\end{tabular}

* Means difference is significant at the level of 0.05 
Á. Vales-Vázquez et al., European football competitive profile

Significant differences were also observed in the second dimension of the scale, the team equality between the teams of the same championships. In this respect, LaLiga showed significantly higher results than Ligue $1(F=4.020 ; p=0.012)$, and values near to be significantly higher than Bundesliga $(F=4.020$; $p=0.082)$ in the Classification Compactness Index. No significant differences were observed between the championships in the other 2 indices of the dimension (Performance Sustainability and Home Advantage indices).

In the last comparison, LaLiga obtained significantly higher values in the Match Openness Index than Ligue $1(F=7.873 ; p=0.028$. In the same line, Bundesliga scored with significantly higher values than Serie $\mathrm{A}(F=7.873 ; p=0.012)$, Ligue $1(F=7.873 ; p<$ $0.000)$, and Liga Portugal championships $(F=7.873$; $p=0.003)$. Although differences were not significant, the Premier League scored higher values near to be significant than Ligue $1(F=7.873 ; p=0.065)$ in the Match Openness Index.

Regarding the second index of the type of the match dimension, Match Equality Index, the Premier League had significantly higher results than Bundesliga $(F=$ 4.097; $p=0.018$ ). Ligue 1 also showed significantly higher results than Bundesliga $(F=4.097 ; p=0.010)$. In the same line, although differences were not significant, Liga Portugal also reached higher values than Bundesliga in the Match Equality Index ( $F=4.097 ; p=$ 0.096). Finally, no significant differences were observed in the third index of the dimension, Result Uncertainty Index.

\section{DISCUSSION}

The purpose of the research was to compare the competitive profile of the best-ranked championships that currently comprise the European football scene (Spanish LaLiga, English Premier League, German Bundesliga, Portuguese Liga Portugal, French Ligue 1, and Italian Serie A) with a contextualized instrument applying performance indicators. The findings showed significant differences between the championships in the 3 dimensions of the BIACPC scale: (1) excellence of the championship; (2) team equality; (3) type of the match. Spanish LaLiga was the only championship that scored suitable results for the features of all the indices and dimensions designed in the battery.

The battery of indicators used in this study allowed the collection of new and original indicators from a multi-directional perspective of the performance analysis. Thus, the battery was designed by using different performance indicators (i.e. the use of indices such as the international prestige or the classification index). Similar global indicators have been applied previously $[7,18,21]$. This emphasizes the importance of implementing new measurement indices to enhance comprehension and interpretation and the competitive peculiarities of a championship from different perspectives. Specific results observed in the 3 dimensions of the BIACPC used in this study are discussed below.

Competitive profile: excellence of the championship

LaLiga showed a high degree of international prestige compared with the rest of the championships analysed. The findings revealed that LaLiga obtained the highest values in the International Achievement and Classification Dominance indices. Significant differences were observed in some cases. It means that the LaLiga Spanish championship ranks at the top of the European championships in terms of the competitive strength owing to the international participation of the teams (i.e. Real Madrid, F.C. Barcelona, Atl. Madrid, and Sevilla F.C.). In contrast, the French championship Ligue 1 achieved the lowest level in both indicators, which positions it among the lower rankings. However, no significant differences were observed between Ligue 1 and other championships. Thus, new parameters need to be analysed (i.e. the socio-spatial constraints of the teams/championships) to help understand the differences of the construct competitive profile.

In respect to other championships, the comparison of the data obtained in this study with those analysed by Sarmento et al. [20] indicates the loss of international prestige in the case of the Italian Serie A championship in recent years. According to the International Federation of Football History and Statistics [24], Serie A was considered one of the 3 most important European championships during the first decade of the $21^{\text {st }}$ century, along with the English Premier League and the Spanish LaLiga championships. Thus, a deep analysis of the factors that influence the competitive profile of the international championships is necessary.

In these terms, something similar to the decrease of Serie A international prestige has been observed in the English Premier League. Even though there is a direct connection between the financial potential of the teams/championships and their sporting successes [25], it is also noted that the English championship (the richest) is falling behind the Spanish LaLiga and the German Bundesliga championships in the indicators related to the competitive excellence of 
the teams belonging to the same championship. This provides evidence that the greater financial power of the Premier League is failing to assure its success in European competitions at the highest level $[15,16]$.

\section{Competitive profile: team equality}

The findings showed differences between the Spanish LaLiga and the French Ligue 1 championships in the Classification Compactness Index. However, no differences were observed in any other index of the team equality dimension (Performance Sustainability or Home Advantage indices) between the championships. The fact that LaLiga championship had higher results than Ligue 1 could be related to the presence of its 3 excellence teams (Real Madrid, F.C. Barcelona, and Atl. Madrid), which achieved highest performance levels in the last years. These teams obtained more than $75 \%$ of the points played in their championship. Therefore, a deeper comprehension of the factors that influence the competitive profile of a team/championship could provide relevant information for study purposes.

In the same way, a tendency was observed within each of the championships analysed here confirming that the same one or a small group of teams win a greater percentage of the championship points. In this respect, the payroll analysis developed here reveals that there are only 14 champion teams, compared with the 30 potentially winning teams in the championships (i.e. Juventus in the Italian championship, Porto and Benfica in the Portuguese, B. Munich and B. Dormund in the German, or Montpellier and PSG in the French championship).

Several studies that analysed the degree of competitive balance of the teams brought findings similar to the results observed here regarding the Classification Compactness Index [19, 21, 26]. Moreover, with respect to the Home Advantage Index, the data showed that the so-called home advantage effect operated in all European championships with different incidence levels, depending on the championship under analysis [27-29], although significant differences were not observed. If one compares the results of this study with those obtained by Pollard [30], the average percentage of wins by teams playing at home in the European elite championships turns out analogous.

In this context, there is a tendency towards the reduction of the effect of playing at home by around $4 \%$ over time when comparing the 1997-2003 period with 2011-2016. The findings here indicate that the lowest percentage of home victories occurred in the Premier League English championship, despite the fact that it is the second only to the German Bundesliga in the level of support in the stadiums and crowd pressure in favour of the home team [16]. This suggests that other factors are as important as the crowd attendance, e.g. the effects of travel on the physical condition of the visitors, familiarity with the playing conditions, refereeing decisions, tactical adaptations, or psychological factors exert an influence on the home advantage [30-32]. These are other research lines that should be studied together in the future.

\section{Competitive profile: type of the match}

According to the analysis dimension related to the type of matches, the significantly higher Match Openness scores observed in the Bundesliga German and LaLiga Spanish championships suggest that their teams play a more open style of football than the teams in the rest of the championships analysed. These findings partially agree with those obtained by Oberstone [11], who confirmed that during the 2008-2009 season, in LaLiga there was a higher goal average per game than in Serie A or the Premier League. These results were also noted by Pinochet [15], who verified that, among the main European championships, the German Bundesliga had the highest average number of goals per game during the 2013-2014 season. However, the absence of significant differences in the measurement indices related to Match Equality (except for the German Bundesliga) and Result Uncertainty indices evidenced a high degree of equality of the championships analysed (i.e. in the final results of the matches and in the degree of uncertainty and competitive tension).

In summary, the data observed are in line with those already identified by Vales-Vázquez [3]. Thus, they confirm that the so-called globalization effect, so characteristic of other social orders such as the political or economic spheres, is also influencing football. In this case, the number of common traits increasingly outweighs the differential traits. It was observed when comparing performance levels and the way the game was played by the elite teams from different countries or continents. According to Castelo [31] and ValesVázquez [3], the main cause for the global homogenization process, typical of the current football scene, is embodied in the continuous blending of soccer cultures. It is a consequence of the intense transfer market and player loans among teams of different countries, all of which results in the disappearance of some football academies. As a case in point, around $63 \%$ of the players who took part in the last two world championships, held in South Africa in 2010 and in Brazil in 
Á. Vales-Vázquez et al., European football competitive profile

2014, habitually played in foreign championships [32]. Therefore, more studies are necessary to determine the key causal factors that affect the competitive profiles of the best international football teams and championships.

\section{CONCLUSIONS}

The analysis of the data collected confirms different competitive profiles of the best-ranked championships. These differences were observed mainly in the indices related with the international prestige and the competitive quality of the teams. In this sense, the Spanish LaLiga championship stands out as the only instance of a suitable competitive profile. Consequently, LaLiga occupies the highest positions in the ranking in all the measurement dimensions and indices collected using the BIACPC. The results of this new research line and study are relevant for future research attempting to compare the competitive profiles of teams and championships.

The results obtained by the use of measures such as the BIACPC will allow to determine which championships represent higher levels of demand and competitive balance. In the same line, the use of their indices could help assess what championships are perceived as more attractive for spectators, sponsors, or communications media in general. Finally, coaches and sports leaders could also apply the information of the BIACPC to draw overall conclusions about the competitive peculiarities of a championship. For example, information would be essential in order to define more proficient intervention strategies from both the technical-tactical (e.g. setting up the ideal model of play for the team or composing the team squad) and a club's economic-financial standpoint to manage investment policies or sponsorship models.

\section{Acknowledgments}

The authors consider that they have no potential conflict of interest concerning the content of the present study with third persons or entities. They are grateful for the support provided by LaLiga (Spanish professional football championship) in the preparation of the research.

\section{Disclosure statement}

No author has any financial interest or received any financial benefit from this research.

\section{Conflict of interest}

Authors state no conflict of interest.

\section{References}

1. Nevill A, Atkinson G, Hughes M. Twenty-five years of sport performance research in the Journal of Sports Sciences. J Sports Sci. 2008;26(4):413-426; doi: 10.1080/02640410701714589.

2. McGarry T. Applied and theoretical perspectives of performance analysis in sport: scientific issues and challenges. Int J Perform Anal Sport. 2009;9(1):128-140; doi: 10.1080/24748668.2009.11868469.

3. Vales-Vázquez A. Soccer: from the analysis of the game to the edition of technical reports [in Spanish]. Pontevedra: McSports; 2012.

4. Sánchez-Sánchez J, Hernández D, Casamichana D, Martínez-Salazar C, Ramirez-Campillo R, Sampaio J. Heart rate, technical performance, and session-RPE in elite youth soccer small-sided games played with wildcard players. J Strength Cond Res. 2017;31(10):26782685; doi: 10.1519/JSC.0000000000001736.

5. Ramírez-Campillo R, González-Jurado JA, Martínez C, Nakamura FY, Peñailillo L, Meylan CM, et al. Effects of plyometric training and creatine supplementation on maximal-intensity exercise and endurance in female soccer players. J Sci Med Sport. 2016;19(8):682687; doi: 10.1016/j.jsams.2015.10.005.

6. Neale WC. The peculiar economics of professional sports: a contribution to the theory of the firm in sporting competition and in market competition. Quart J Econ, 1964;78(1):1-14; doi: 10.2307/1880543.

7. Pérez-González B, Pérez-Espés C, Cazurro Barahona V, Gálvez Ruiz P. Comparative study of the competitive balance of five European football leagues in the period 2000-2015 [in Spanish]. Rev Intercon Gest Desport. 2016;6(1):73-84.

8. Hägglund M, Waldén M, Bahr R, Ekstrand J. Methods for epidemiological study of injuries to professional football players: developing the UEFA model. Br J Sports Med. 2005;39(6):340-346; doi: 10.1136/bjsm.2005.018267.

9. Walls RJ, Ross KA, Fraser EJ, Hodgkins CW, Smyth NA, Egan CJ, et al. Football injuries of the ankle: a review of injury mechanisms, diagnosis and management. World J Orthop. 2016;7(1):8-19; doi: 10.5312/wjo.v7.i1.8.

10. Dellal A, Chamari K, Wong DP, Ahmaidi S, Keller D, Barros R, et al. Comparison of physical and technical performance in European soccer match-play: FA Premier League and La Liga. Eur J Sport Sci. 2011;11(1):5159; doi: 10.1080/17461391.2010.481334.

11. Oberstone J. Comparing team performance of the English Premier League, Serie A, and La Liga for the 20082009 season. J Quant Anal Sports. 2011;7(1):1-18; doi: 10.2202/1559-0410.1280.

12. Sarmento H. Football game analysis. Patterns of offensive play in high-performance teams: a qualitative approach [in Portuguese]. Doctoral thesis. Vila Real: Universidade de Trás-os-Montes e Alto Douro; 2012.

13. Quirk J, Fort RD. Pay dirt: the business of professional team sports. Princeton: Princeton University Press; 1997.

14. Llaneras K. La Liga in data: between inequality and 
excellence [in Spanish]. Jot Down; 2014. Available from: http://www.jotdown.es/2014/02/la-liga-de-futbol-en-datos-entre-la-desigualdad-y-la-excelencia/.

15. Pinochet JM. Which is the best football league in the world? [in Spanish]. BBC Mundo, Deportes; 2015. Available from: http://www.bbc.com/mundo/noticias/2015/ 03/150310_deportes_futbol_mejor_liga_europa_ premier_league_champions_jmp.

16. Boor S, Green M, Hanson C, Shaffer A, Thorpe A, Winn C. Annual review of football finance 2016. London: Deloitte; 2016. Available from: https://www2. deloitte.com/content/dam/Deloitte/uk/Documents/ sports-business-group/deloitte-uk-annual-review-offootball-finance-2016.pdf.

17. Goossens K. Competitive balance in European football: comparison by adapting measures: national measure of seasonal imbalance and top 3. Antwerp: University of Antwerp, Research Administration; 2005.

18. Michie J, Oughton C. Competitive balance in football: trends and effects. London: Football Governance Research Centre; 2004.

19. Naghshbandi S, Yousefi B, Etemad Z, Moradi M. The comparison of competitive balance in football premier leagues of England, Germany, Spain, France, Italy and Iran: a case study from 2009-2010 season. J Hum Sport Exerc. 2011;6(4):673-681; doi: 10.4100/jhse.2011.64.10.

20. Sarmento H, Pereira A, Matos N, Campaniço J, Anguera TM, Leitão J. English Premier League, Spain's La Liga and Italy's Serie's A - what's different? Int J Perform AnalSport. 2013;13(3):773-789; doi: 10.1080/24748668. 2013.11868688.

21. Gasparetto T, Barajas Á. Analysis of the competitive balance due to accumulated points difference [in Spanish]. Paper presented at the conference: XXV Jornadas Hispano Lusas de Gestión Científica, Ourense; 2015.

22. Montes F, Sala R. Competitive balance in the First Division Spanish soccer league: a Montecarlo test on functional data [in Spanish]. Estud Econ Apl. 2012;30(2): 513-526.

23. Coefficients of clubs by federations [in Spanish]. UEFA; 2017. Available from: https://es.uefa.com/memberassociations/uefarankings/country/index.html.

24. The strongest league in the world 2015. International Federation of Football History and Statistics; 2016. Available from: iffhs.de/the-strongest-league-in-theworld-2015/.

25. Dietl H, Franck E. Efficiency problems in sports leagues with profit-maximizing corporations. A model-theoretical investigation [in German]. In: Büch M-P, Schellhaaß H-M (eds.), Economics of sports leagues [in German]. Schorndorf: Hofmann; 2005; 29-52.

26. Del Corral J. A picture is worth a thousand words: analysing competitive balance in European football leagues from 2007-2013. Paper presented at the IX Gijón Conference on Sport Economics: Neale Golden Anniversary. Gijón; 2014.

27. Morris D. The soccer tribe. London: Cape; 1981.
28. Pollard R. Home advantage in football: a current review of an unsolved puzzle. Open Sports Sci J. 2008;1(1):1214; doi: 10.2174/1875399X00801010012.

29. Pollard R, Gómez MA. Comparison of home advantage in men's and women's football leagues in Europe. Eur J Sport Sci. 2014;14(Suppl 1):S77-S83; doi: 10.1080/ 17461391.2011.651490.

30. Pollard R. Worldwide regional variations in home advantage in association football. J Sports Sci. 2006;24(3): 231-240; doi: 10.1080/02640410500141836.

31. Castelo JF. General football treaty: practice guide of training exercises [in Spanish]. Barcelona: Editorial Paidotribo; 2009.

32. Serra-Olivares J, Pastor-Vicedo JC, González-Víllora S, Teoldo da Costa I. Developing talented soccer players: an analysis of socio-spatial factors as possible key constraints. J Hum Kinet. 2016;54:227-236; doi: 10.1515/ hukin-2016-0050. 